\title{
A Comparative study of vocal music education between China and the United States
}

\author{
Yuhang Zhang \\ Conservatory of Music, Emporia State University, Emporia, USA, Nanjing Normal University, \\ Nanjing, China \\ Email:1334757583@qq.com
}

Keywords: China and the United States; music education; comparison

\begin{abstract}
As is known to all, China and the United States have different historical and cultural backgrounds, and thus have their own characteristics in the process of carrying out higher normal music education. In order to implement quality education fully, promote the comprehensive development of music education students, this article will focus on the multi-faceted comparison of music education between Chinese and American, and actively absorb the aspects that American music education is worthy of reference, in order to improve the level of music education in China.
\end{abstract}

\section{Introduction}

The differences in music education between China and the United States are the cultural differences between China and the United States. China and the United States are represented in the two cultures of the East and the west respectively. The education of music is accompanied by the culture of China and the United States from the beginning. American music originated from Indian music. Through a long period of growth, American music did not have a unique American musical style until the 20th century. The United States is the world's recognized musical power. Since the reform and opening up of music education in China, many famous musicians, such as Lang Lang and Yundi Li, have also been promoted to the ranks of famous musicians in the world. The United States has a well-developed and well-developed music education system. China's music education system is still in the stage of exploration and exploration. This article will compare the differences of education of vocal music between China and the United States from the experience of the author during his study in the United States.

The improvement of the level of vocal music education requires continuous study and learning. The United States is a relatively advanced country in vocal music education, and it presents many differences with our vocal music education in the entire vocal music teaching process and education model. Different cultural backgrounds and surroundings produce different educational concepts and methods. By analyzing and contrasting, taking its essence and discarding its dross, and combining specific applications, it is of great benefit to improve the level of vocal music education in China. 


\section{Concept of professional music education in China}

In China, music education is an important project for the all-round development of a person. Music education is often used to improve the self-cultivation of people. In the field of music education, China often thinks that it is a kind of skill training, learning music for the purpose of learning music. Master music skills and practice hard, so as to reduce students' creativity and their emotions. Chinese music education was formed in the Western Zhou Dynasty, such as Confucianism, Taoism and so on. They all attach great importance to the education of music and have their own unique ideas of art education. From the development of China's music education, to learn music to cultivate people's noble sentiment and self-cultivation, to cultivate the sentiment of music activities. The main purpose of music education in ancient China is to learn music. It is to train music professionals by teaching music as the main way of learning music as the main purpose. Chinese music education has been the thought of "learning art" from ancient times to the present, but this thought is influenced by many aspects such as social economy, activity, cultural life and so on. The understanding of music education is only a way to develop intelligence. It only plays an auxiliary role, and it does not recognize that music plays an important role in personal development. Therefore, the beauty of music, and other functions cannot be truly realized, regard music as an auxiliary means, but ignore the factors and values of music itself, far from playing the true meaning of music itself.

\section{Concept of professional music education in the United States}

American music educators generally believe that music education can make students fully enjoy learning music, and more importantly, accumulate music experience. The key is to cultivate students' creative ability and independent thinking. There are many famous music colleges in the world in the United States, but in addition to this, many colleges and universities specializes in the school of music and give students a diploma in music. Learning music is the process of learning to learn. Learning music is learning imagination and self-expression. Of course, learning music is also a process of learning and learning, as well as a study of expressive power and imagination. In the field of music education, the United States is inclined to cultivate the quality of music. It takes music as an important expression of expression of self and attaches great importance to its own creation and appreciation ability. Their music education has different forms. Music and art education promotes each other's education, music and art education and other subject's education. The vocal music education in the United States developed relatively early, enjoyed a high reputation in the world, and is a place where world-class musicians gather. I have been studying in Emporia state university for 2 years in the United States. Through learning and research, I have some intuitive understanding of vocal music learning in U.S. colleges and universities and felt the differences in vocal music teaching under different cultural backgrounds and environments, which led to the reflection on the current state of vocal music teaching in China.

\section{Compare Chinese and American vocal music education}

\subsection{Vocal music interview}

Understanding the sound and body structure, when I first entered the piano room of the professor, I found that various structures and human body models were placed in their rooms. I doubted that I walked into a hospital and then taught like a doctor. Like to sympathize with you about your voice and body condition. If you feel good, it will be a sound practice. The professors will understand what the student is suitable for in the process of playing the scales. They will 
initially judge the student's voice. However, this is not the final result, because positioning the students is a long process. The professor will give conclusions based on the student's tone and the student's most suitable range.

On the other hand, learning methods are also very important for vocal students, so in the first few classes, the instructor will let you observe the structure of the human body and understand the oral cavity, vocal cords, chest resonance, lungs, etc. The singing-related body structure is also a student's knowledge to be understood. In the United States, music learning will also take courses on vocal music and body structure. Through such learning, you can change your voice habits, correct your voice errors, and make your own voice.

This is a very scientific education. In the case of students mastering basic knowledge and understanding themselves, the teacher gives students a review and then divides the vocabulary, which is very conducive to the future development of a student.

\subsection{Warm up exercises before singing}

During my study in the United States, whether it was a vocal music lesson, an opera performance or choir, as long as it was about vocal music, before each class, the professors would lead the students to a set of warm-up exercises, which includes exercises from head and neck movements to shoulder movements, to waist and legs to the body, and breathing exercises during warm-up exercises. For example, during the course of making a double-armed circle, you keep your arms in a startled inhale as they stretch out over your head, then pause and slowly drop your arms along with the pronunciation "Si" or "Yi". You can also maintain your pronunciation and keep your arms swinging many times on either side of your body to strengthen the practice of lung capacity.

This seemingly simple set of pre-singing warm-up movements has benefited me greatly and inspired me. It not only moved the muscles of the throat, but also fully mobilized the muscles of the whole body, so that these muscles could actively participate in the movement of singing. The whole person is no longer speaking alone through the throat, but more like the operation of a singing machine. Especially in the cold winter, the role of warm-up exercise is even more obvious. However, there are few warm-up exercises in vocal music classes in our country. If we can add this training to our vocal music classroom and allow students to fully mobilize the singing muscles through warm-up exercises, this will greatly help solve the problem of ossified sound.

\subsection{The selection of verses for vocal practicing and songs}

In the United States, many vocal music teachers have their own verses for vocal practicing. Their verses for vocal practicing are varied, such as songs taken from famous verses for vocal practicing, self-edited songs, large-line exercises, silent exercises, multi-letter exercises, and exercises of rapid melody with English lyrics, etc. And for different parts they all have a lot of corresponding verses for vocal practicing. In Dr. Speedie's vocal music class, you need to know how to relax your body and find the most comfortable state. You can make sure your voice is natural on this way. Secondly, she believes that only singing well enough for a good performance can sing better. Therefore, in the course of class, verses for vocal practicing and songs often occupy the same amount of time and weight. In the choice of songs, American teachers hope that students will sing more art songs, which will help young students to establish the correct singing state. Artistic songs with profound artistic connotation also play an important role in improving students' musical accomplishment.

Chinese vocal music classes are often too single and casual to verses for vocal practicing, and most of the focus is on singing, which weakens the effectiveness of verses for vocal practicing. If we strengthen the development and practice of verses for vocal practicing and let students experience more vocal music skills in the verses for vocal practicing, I think it will bring more help 
to our concert. In addition, our teachers and students also like to display the ability to sing in large works in the selection of tracks. They have strong utilitarian learning, and they are not patient enough in the study and singing of art songs, which is our domestic vocal music teaching easy to appear on the problem.

\subsection{Teaching methods based on encouragement and guidance}

The American vocal music class uses the one-on-one teaching method like China, but the classroom atmosphere in the United States is light and lively compared to China. Teachers often speak very humorous words in the classroom, even mimicking the sounds and forms of some animals. They are so naive that they can't help but laugh. In addition, because of the different educational models, the American students are more relaxed and unrestrained, and their singing is fluent, making the classroom atmosphere very harmonious. In the teaching process, American vocal teachers use the methods of encouragement and praise to treat students' performance. No matter how the students sing, teachers first encourage them and then correct them according to specific issues. In this way, the teacher is no longer the master and occupant of the classroom, but the guide and the motivator of the students' study. They think that a successful vocal music teacher is not only to teach students how to learn scientific vocal skills, but also how to stimulate students' enthusiasm for learning and develop students' creative thinking ability, as well as establishing good study habits and methods, and helping students to establish lofty ideals and immediate goals, to help them achieve their maximum.

The atmosphere in Chinese vocal music classes is more serious, and students are also more restrained and reserved. In addition to the fact that for a long time there has been a tradition of teachers carrying apprentices and teachers with dignity, students should listen to their teachers' demands and should not take a skeptical attitude. The so-called strict teacher can be a high student. When there are flaws in the practice, they always criticize the former and correct it later, not much encouragement. Of course, this has something to do with our country's historical heritage and educational model. Comparing the two teaching methods, I think that there are both advantages and disadvantages, too much encouraging teaching is not completely suitable for Chinese students, but teachers' classroom humor visualization is worthy of our reference and learning.

\section{Course setting and development of comprehensive ability}

American colleges and universities adopt flexible credit system in teaching system, students can choose courses for themselves according to their interests and their own conditions, and they can graduate after taking full credit, so it is very common for students to choose courses across majors.

The curriculum of Emporia state university in the United States is also relatively rich. There are music skill courses, such as vocal music skill, piano skill, chorus, ensemble, music quality, etc. There are music quality classes such as music theory, solfeggio, music skills classes, etc. There are also some extended courses such as Native American Music History, Recording Arts, Vocal Music Education, Ethnomusicology, History of Jazz, etc. Students have greater autonomy in the selection process, and they can choose more than two majors to study, and they can even take courses in other colleges to fully explore their own potential. American colleges and universities pay special attention to the cultivation of students' comprehensive ability, which is not only reflected in the curriculum and credit selection, but also creates a lot of practical opportunities for students. Take the Emporia state university music department, for example, where they set up several professional practice concerts at the middle of each semester, as well as occasional conversions of various skill courses, as well as concerts for academic exchanges. Let every student have the opportunity to show on stage. 


\section{Conclusion}

During the two years of study in the United States, I took a lot of courses and learned the teaching principles of student-centered education in American colleges and universities, as well as relaxed and rigorous teaching methods, and got a lot of inspiration for vocal music teaching. However, I think there are also some drawbacks in American vocal music education. For example, teaching methods with excessively encouraged and praised will increase students' self-confidence, but they will also give students a sense of pride and not be able to objectively recognize their own problems; although an over-relaxed and free classroom atmosphere will allow students to study without stress, it will also result in students lacking motivation to learn and the results of teaching are not significant enough. In my opinion, moderate combination of relaxed and strict is more conducive to the study of vocal music. Nowadays, with the rapid development of China, our vocal music education also keeps pace with the times, and the gap between our vocal music education and the education level of advanced countries is also shrinking. Because of the difference of national conditions and education, our teaching also has its own characteristics and advantages. In order to further improve the level of vocal music teaching, we should not only carry forward our strong points, but also the foreign advanced teaching concepts and our teaching characteristics of the integration, better with the international standards.

\section{References}

[1] Duan, yike. (2016). Comparative Analysis of Music Education in Chinese and American universities. Music creation.

[2] Wu, tingting. (2015). Comparative Analysis of Chinese and American Music Teachers' Education Courses. Chengdu: Journal of Chengdu Normal University. 